\title{
El premio Nobel de Fisiología y Medicina 2005
}

\author{
Miguel Guzmán
}

Cuando los nombres de Barry J. Marshall y J. Robín Warren fueron proclamados como los ganadores del premio Nobel de Fisiología y Medicina en su versión de 2005, no hubo ninguna sorpresa pero sí una gran satisfacción en la comunidad médica internacional. No hubo sorpresa porque Marshall y Warren eran dos nombres muy familiares para el común de los médicos; en cambio, la complacencia fue total ya que el médico practicante veía en ese hecho la mejor recompensa a un trabajo que desde hace más de dos décadas hizo dar un giro de ciento ochenta grados a conceptos y criterios que se consideraban sólidamente establecidos y casi inmutables dentro de la clínica de la enfermedad ácido-péptica (1).

Warren, un experimentado patólogo clínico, y Marshall, un clínico gastroenterólogo, joven y entusiasta, ambos australianos vinculados al Royal Perth Hospital, conformaron un excelente equipo de trabajo que desde su publicación inicial aparecida en Lancet en 1983, llamó la atención sobre un "bacilo curvo no identificado en el epitelio gástrico en gastritis crónica activa" (2) abriendo así un fascinante capítulo de la medicina contemporánea en el cual y desde entonces han venido sorprendiendo al mundo médico con hallazgos desconcertantes.

Mirado inicialmente con total escepticismo, fue la persistencia de los dos investigadores aunada al recurso técnico del endoscopio de fibra óptica lo que permitió el estudio de cientos de biopsias en donde la presencia del microorganismo era tan persistente como para pasarla inadvertida, como honestamente lo reconocieron antes de ellos numerosos investigadores quienes habían observado estos microorganismos pero interpretaron su presencia con el criterio fácil y simplista, de microorganismos contaminantes (3).

Correspondencia:

maguzmanu@unal.edu.co
La agudeza de Warren al observar en la microscopía electrónica al microorganismo enclavado en sitios de la mucosa gástrica como queriendo escapar del pH ácido y hostil, lo llevó al convencimiento de que debería existir una estrecha relación entre este hallazgo con una patología gástrica muy frecuente como la gastritis. Lenta y persistentemente los hechos fueron demostrando no simplemente una relación con los procesos patológicos sino su papel protagónico como agente etiológico, todo lo cual condujo a otros investigadores a postular hipótesis que fueron convirtiéndose en realidades.

El destacado patólogo colombiano Pelayo Correa pudo trazar la continuidad de los eventos patológicos generados como consecuencia de la acción crónica sobre la mucosa gástrica del ahora reconocido como Helicobacter pylori, eventos que, al término de los años, podían terminar en un carcinoma gástrico. Todo ello lo llevó a preguntarse: ¿es el carcinoma gástrico una enfermedad infecciosa? (4). Todo parece indicar que sí; hoy los estudios tienden a mostrar que la relación entre $H$. pylori y cáncer gástrico es tan estrecha como la que existe entre el consumo de cigarrillo y el carcinoma broncopulmonar (5-8).

Sustentado el principio del papel etiológico de $H$. pylori en la gastritis antral, la úlcera duodenal y la úlcera gástrica, su manejo terapéutico tuvo un cambio radical: atrás quedaron las rigurosas dietas, los complejos esquemas terapéuticos y, en ocasiones, las riesgosas soluciones quirúrgicas, todo a cambio de un manejo combinado simple y de probada eficacia (9), trayendo así una solución a cientos de miles de pacientes en el mundo.

Como si ello no fuera suficiente, Marshall y Warren al sacarlo a la luz, como protagonista biológico de una de las patologías más frecuentes del hombre, lograron que la atención de cientos de 
investigadores se centrara sobre este microorganismo a tal punto que no es una exageración afirmar que $H$. pylories en el campo de la bacteriología médica el mi-croorganismo más exhaustivamente estudiado (10), tan solo comparable al virus de la inmunodeficiencia humana en el campo de la virología.

Cerca de treinta mil artículos publicados en reconocidas publicaciones científicas así lo confirman, su genoma ha sido estudiado hasta en los más íntimos detalles, todos los mecanismos de "encendido y apagado" de los controles genéticos que gobiernan la síntesis de su complejo equipo enzimático han sido dilucidados $(11,12)$, los mecanismos de la respuesta inmune que su presencia crónica despierta y que contribuyen de manera relevante a la generación de los procesos patológicos han sido esclarecidos (13) y quedan, además, abiertas ampliamente las puertas para investigaciones futuras que nos habrán de decir si será necesario erradicar profilácticamente del hombre al modesto microorganismo (14) y si, como ya se insinúa, una vacuna efectiva aparecerá en el horizonte (15).

Por todo lo anterior es que uno tiene que admitir que con este premio Nobel de Medicina adjudicado a Marshall y Warren se ha honrado con toda justicia a dos grandes de nuestro tiempo.

\section{Referencias}

1. Parsonnet J. Clinician-Discoverers-Marshall, Warren and H. pylori. N Engl J Med 2005;353:2421-3.

2. Marshall BJ, Warren JR. Unidentified curved bacillus on gastric epithelium in active chronic gastritis. Lancet 1983;1:1273-5.

3. Marshall BJ. Helicobacter pioneers: firsthand accounts from the scientist who discovered helicobacters, 18921982. Victoria, Australia: Blackwell; 2002
4. Correa P. Is gastric carcinoma an infectious disease? N Engl J Med 1991;325:1170-1.

5. Muñoz N. Is Helicobacter pylori a cause of gastric cancer? An appraisal of the seroepidemiological evidence. Cancer Epidemiol Biomarkers Prev 1994; 3:445-51.

6. Hansson LE, Nyren O, Hsing AW, Bergstrom R, Josefsson S, Chow WH et al. The risk of stomach cancer in patients whit gastric or duodenal ulcer disease. N Engl J Med 1996;335:242-9.

7. Correa P. Human gastric carcinogenesis: a multistep and multifactorial process. First American Cancer Society Award Lecture on Cancer Epidemiology and Prevention. Cancer Res 1992;52:6735-40.

8. Uemura N, Okamoto S, Yamamoto S, Matsumura $\mathrm{N}$, Yamaguchi S, Yamakido $\mathbf{M}$ et al. Helicobacter pylori infection and the development of gastric cancer. N Engl J Med 2001; 345:784-9.

9. Fox JG, Wang TC. Helicobacter pylori Not a good bug after all. N Engl J Med 2001;345:829-32.

10. Suerbaun S, Michetti P. Helicobacter pylori infection. N Engl J Med 2002;347:1175-86.

11. Tomb JF, White O, Kerlavage AR, Clayton RA, Sutton GG, Fleischmann RD et al. The complete genome sequence of the gastric pathogen Helicobacter pylori. Nature 1997;388:539-47.

12. Lee A. The Helicobacter pylori genome. New insights into pathogenesis and therapeutics. N Engl J Med 1998;338:832-3.

13. Blanchard TG, Czinn SJ. Immunology of Helicobacter pylori and prospects for vaccine. Gastroenterol Clin North Am 2002;29:671-85.

14. Taylor DN, Blaser MJ. The epidemiology of Helicobacter pylori infection. Epidemiol Rev 1991;13:42-9.

15. Calvet X, Garcia N, Lopez T, Gisbert JP, Gene E, Roque M. A meta-analysis of short versus long therapy with a proton pump inhibitor, clarithromycin an either metronidazole or amoxycilline for treating Helicobacter pylori infection. Aliment Phamacol Ther 2000;14:603-9. 